\title{
Effect of Acidic and Basic Medium on Celecoxib by UV Spectroscopy
}

\section{Safila Naveed ${ }^{1,2 *}$, Fatima Qamar ${ }^{1,2}$ and Syeda Zainab ${ }^{1,2}$}

${ }^{1}$ Department of Pharmaceutical Chemistry, Faculty of Pharmacy, Jinnah University for women Karachi, Karachi, Pakistan

${ }^{2}$ Department of Pharmaceutical Chemistry, Faculty of Pharmacy, University of Karachi, Karachi, Pakistan

\begin{abstract}
Degradation is a main problem in numerous unstable products. Our study on drug substance involves Acid/ base Stress testing. In our recent research we study the effect of different environmental conditions by subjecting the different brands of pharmaceutical formulation i.e. celecoxib (Nuzib, Seleco, Celbexx) under acidic and basic conditions by using spectrophotometer. It is usually preferred over other methods because of less equipment cost and economical maintenance advantage. When celecoxib (Nuzib, Seleco, and Celbexx) subjected to $0.1 \mathrm{~N} \mathrm{HCl}$ and $0.1 \mathrm{~N} \mathrm{NaOH}$, celecoxib showed decreased availability in acidic medium as well as in alkaline medium. The absorbance in basic medium of different brands of celecoxib i.e., Nuzib, Seleco and Celbexx was found to be $0.055,0.094,0.071$ and their percent availability was found to be $50 \%, 42.30 \%, 35.14 \%$. In acidic medium the absorbance of Nuzib, Seleco and Celebex was found to be $0.047,0.128,0.074$ percent availability was $42.70 \%$, $57.60 \%, 36.63 \%$. We conclude that the absorbance of all brands of celecoxib decreases in acidic and basic medium which is due to the degradation of celecoxib in both mediums.
\end{abstract}

Keywords: Celecoxib; Acidic medium; Basic medium; U.V spectrophotometer

\section{Introduction}

The first cyclo-oxygenase (COX)-2 selective inhibitor introduced into clinical practice was celecoxib. Coxibs have anti-inflammatory and analgesic activity but without gastrointestinal toxicity like other non selective NSAIDS. To minimize the risk of cardiovascular diseases, we should use the lowest effective dose of celecoxib but for the shortest possible duration and after a careful evaluation of the cardiovascular, renal risks and GI, of the individual patient [1]. Celecoxib and curcumin, which is a natural antioxidant and also an anti-inflammatory agent, have been found to be useful in alleviating the ulcerative colitis [2]. Celecoxib is found to inhibit the proliferation of gastric cancer cell [3]. Celecoxib is a selective cyclooxygenase-2 inhibitor, has found to have antitumor activity [4]. For osteoarthritis, Celecoxib is an effective treatment [5]. Cytochrome P450 (CYP450) enzymes, mainly CYP2C9 and CYP3A4 are the enzymes which metabolizes the celecoxib in body [6] (Figure 1).

\section{Experimental}

\section{Material and reagents}

Pyrex glass including measuring volumetric flask, cylinder, beakers, pipette, funnel and stirrer were used. All glass wares were first washed with chromic acid then with water and finally rinsed with freshly prepared double distilled water. Reagents were of Analytical grade reagents $0.1 \mathrm{~N}$ Sodium hydroxide, $0.1 \mathrm{~N}$ Hydrochloric acid and de-ionized water or double distilled water.

\section{Instruments}

Ultraviolet Lamp Power of 8N, Serial NO: N 045571, LF-204. LS ' $4 \mathrm{~W}-254$ and $365 \mathrm{~nm}$ ', Spectrophotometer with a quartz cuvette T80 UV-VI spectrometer 'PG Instrument', Weighing Balance Item PA214C: 'Pioneer OHAIUS' and Water Bath 'HH-4' having digital and constant temperature tank.

\section{Preparation of $0.1 \mathrm{~N}$ Hydrochloric acid and Sodium hydroxide}

4 grams of sodium hydroxide is transferred in $100 \mathrm{ml}$ volumetric flask and dissolved in small quantity of water and finally volume was made up to mark of the flask with de-ionized water.
$8.3 \mathrm{ml}$ analytical grade hydrochloric acid having $37 \%$ purity and 12 $\mathrm{N}$ normality was taken in a volumetric flask and the volume was made up to mark flask with DI water.

\section{Preparation of celecoxib solution}

About 20 tablets of each brand of celecoxib (Nuzib, Seleco, and Celbexx) were weighed and crushed. Average weight was determined $200 \mathrm{ppm}$ of the solution was prepared by weighihing the required amount of the powder to obtain $0.020 \mathrm{~g}$ active. Celecoxib then dissolved in small quantity of water. The solution was then transferred in to a 100 $\mathrm{ml}$ volumetric flask finally volume was made up to mark of the flask with de-ionized water. Absorbance was determined at wavelength max $220 \mathrm{~nm}$. The same procedure was repeated for each brand of celecoxib.

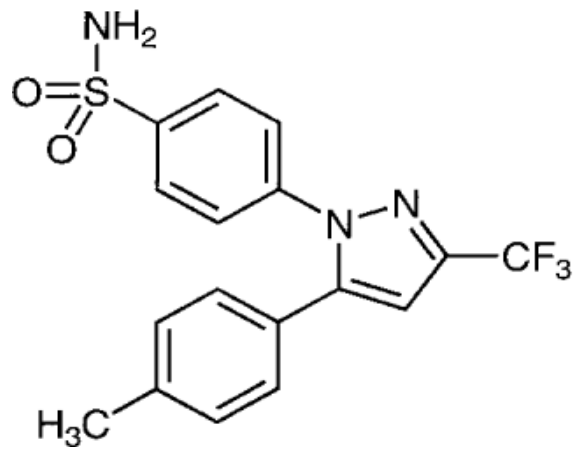

Figure 1: Structure of Celecoxib.

*Corresponding author: Safila Naveed, Department of Pharmaceutical Chemistry, Faculty of Pharmacy, Jinnah University for women Karachi, Karachi, Pakistan, Tel: 00923002621917; E-mail: safila117@yahoo.com

Received May 23, 2015; Accepted June 20, 2015; Published June 25, 2015

Citation: Naveed S, Qamar F, Zainab S (2015) Effect of Acidic and Basic Medium on Celecoxib by UV Spectroscopy. J Nutr Disorders Ther 5: 166. doi:10.4172/2161 0509.1000166

Copyright: $\odot 2015$ Naveed S, et al. This is an open-access article distributed under the terms of the Creative Commons Attribution License, which permits unrestricted use, distribution, and reproduction in any medium, provided the original author and source are credited. 
Citation: Naveed S, Qamar F, Zainab S (2015) Effect of Acidic and Basic Medium on Celecoxib by UV Spectroscopy. J Nutr Disorders Ther 5: 166. doi:10.4172/2161-0509.1000166

\section{Procedure for the study}

For acid and base: To determine the effect of acid and base on Celecoxib, $5 \mathrm{ml}$ of $200 \mathrm{ppm}$ solution of each brand of Celecoxib was transferred in to two separate test tubes then $5 \mathrm{ml}$ of $0.1 \mathrm{~N}$ hydrochloric acid was added in one test tube and $5 \mathrm{ml}$ of $0.1 \mathrm{~N}$ sodium hydroxide was added in another test tube respectively. Then the tubes were left for 30 minutes. The absorbance of the solution was determined using spectrophotometer at wavelength $\max 299 \mathrm{~nm}$ (Tables 1 and 2).

\section{Result and Discussion}

The main objective of this study is to determine the effect of acidic and basic medium on the drug celecoxib .For this reason we prepared a $200 \mathrm{ppm}$ solution of celecoxib. To determine the effect of acid and base on celecoxib the $200 \mathrm{ppm}$ solution of celecoxib was transferred in to two separate test tubes that contain $5 \mathrm{ml}$ of acid $\mathrm{Hcl}$ and base $\mathrm{NaOH}$ separately. Then the tubes were left for 30 minutes. The absorbance of the solution was determined using spectrophotometer at wavelength $\max 299 \mathrm{~nm}$. The result reveals that the drug is degraded more in acidic medium $(0.1 \mathrm{~N} \mathrm{HCl})$ as compared to alkaline medium $(0.1 \mathrm{~N} \mathrm{NaOH})$. In presence of acid the drug is converted to such products that show absorbance at $299 \mathrm{~nm}$. The absorbance in basic medium of different brands of celecoxib i.e., Nuzib, Seleco and Celebexx was found to be $0.055,0.094,0.071$ and their percent availability was found to be $50 \%$, $42.30 \%, 35.14 \%$. In acidic medium the absorbance of Nuzi, Seleco and Celebex was found to be $0.047,0.128,0.074$ percent availability was $42.70 \%, 57.60 \%, 36.63 \%$. Our research group performed these types of studies which is useful for determination of drugs in different media [7-11] (Figures 2 and 3).

\begin{tabular}{|c|c|c|c|}
\hline \multicolumn{4}{|c|}{ Absorbance } \\
\hline Brands & Standard & Acid & Base \\
\hline Nuzib & 0.11 & 0.047 & 0.055 \\
\hline Seleco & 0.222 & 0.128 & 0.094 \\
\hline Celbexx & 0.202 & 0.074 & 0.071 \\
\hline
\end{tabular}

Table 1: Absorbance of Celecoxib.

\begin{tabular}{|c|c|c|c|}
\hline \multicolumn{4}{|c|}{ Percent Availability } \\
\hline Brands & Standard & Acid & Base \\
\hline Nuzib & $100 \%$ & $42.70 \%$ & $50.00 \%$ \\
\hline Seleco & $100 \%$ & $57.60 \%$ & $42.30 \%$ \\
\hline Celbexx & $100 \%$ & $36.63 \%$ & $35.14 \%$ \\
\hline
\end{tabular}

Table 2: Percent availability of Celecoxib.
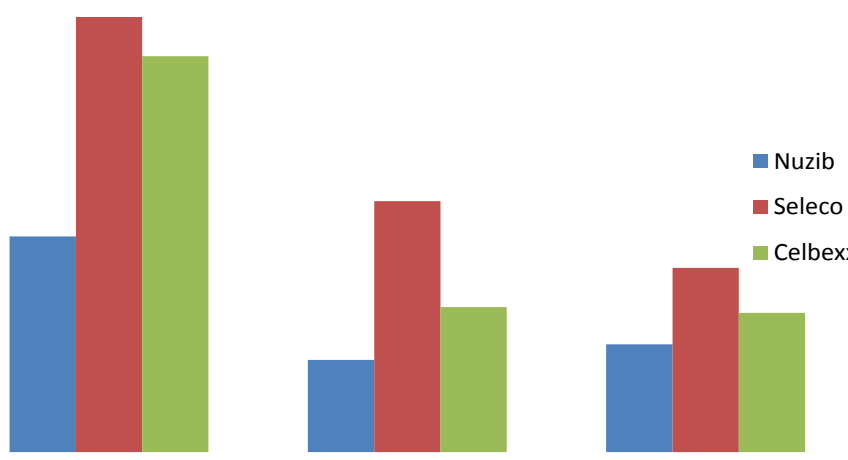

Figure 2: Absorbance of Celecoxib.
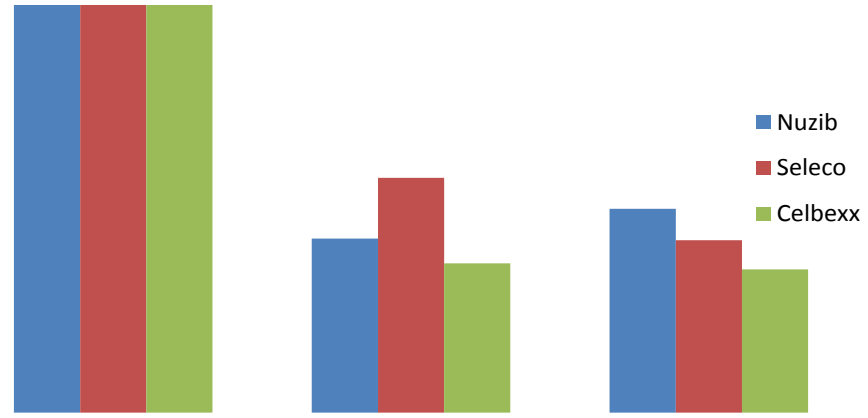

Figure 3: Percent availability of Celecoxib.

\section{Conclusion}

We conclude that the absorbance of all brands of celecoxib decreases in acidic and basic medium which is due to the degradation of celecoxib in both mediums.

\section{References}

1. McCormack PL (2011) Celecoxib: a review of its use for symptomatic relief in the treatment of osteoarthritis, rheumatoid arthritis and ankylosing spondylitis. Drugs 71: 2457-2489.

2. Gugulothu D, Kulkarni A, Patravale V, Dandekar P (2014) pH-sensitive nanoparticles of curcumin-celecoxib combination: evaluating drug synergy in ulcerative colitis model. J Pharm Sci 103: 687-696.

3. Aziz F, Yang X, Wang X, Yan Q, Anti-LeY (2014) J Cancer Res Clin Oncol 2014 Dec 20.

4. Meng C, Lu Z, Fang M, Zhou X, Dai K, et al. (2014) Effect of celecoxib combined with chemotherapy drug on malignant biological behaviors of gastric cancer. Int J Clin Exp Pathol 7: 7622-7632.

5. Essex MN, Behar R, O'Connell MA, Brown PB (2014) Efficacy and tolerability of celecoxib and naproxen versus placebo in Hispanic patients with knee osteoarthritis. Int J Gen Med 7: 227-235.

6. Prieto-Pérez R, Ochoa D, Cabaleiro $T$, Román $M$, Sánchez-Rojas SD, et al (2013) Evaluation of the relationship between polymorphisms in CYP2C8 and CYP2C9 and the pharmacokinetics of celecoxib. J Clin Pharmacol 53: 12611267.

7. Naveed S, Waheed N, Nazeer S (2014) Degradation Study of Different Brands of Cefixime by UV Spectroscopy. Int RJ Pharm Sci 5: 0023-0026.

8. Naveed S, Qamar F, Zainab S, Sarwar G, Usmanghani K (2015) Effect of Acidic and Alkaline Medium on Fexofenadine brands using UV Spectrophotometer Canadian. Journal of Applied Sciences 5: 01-04.

9. Naveed S, Shafiq A, Khan M, Jamal M, Zafar H, et al. (2014) Degradation Study of Available Brands of Metformin in Karachi Using UV Spectrophotometer. J Diabetes Metabolism 5: 328.

10. Naveed S, Waheed N, Nazeer S (2014) Degradation studies of ampicillin in API and formulations. J App Pharm 6: 314 -321.

11. Naveed S, waheed N, Nazeer S (2014) Degradation study of metronidazole in active and different formulation by UV spectroscopy. J Bioequiv Availab 6: 124-127. 